\title{
Design of NHR1100 single loop digital display parameter indicator based on Labview
}

\author{
Fujun Li \\ Instruments and Apparatuses Department, Liaoning Jidian Polytechnic, Dandong City, Liaoning \\ Province 118009,China Zhenxing District, Dandong City, Liaoning Province, Yang He 30th Street \\ lifujun0415@163.com
}

Keywords: Labview; NHR1100; Parameters; Indicator;Design

Abstract. Using MODBUS communication protocol and Labview software platform, through the RS485 communication interface, the display method of NHR1100 single loop digital display function parameters are described in detail according to the serial communication parameter setting device, then realizing the centralized management of digital display control instrument parameters and visual interface.

\section{Introduction}

NHR1100 series single loop digital display control instrument (referred to digital display control instrument) use differential advance control algorithm, high control precision, no overshoot, fuzzy self-tuning function. It can be used with all types of sensors and transmitters, realizing the measurement display of temperature, pressure, liquid level, capacity, speed and other physical quantity, and coordinating with a variety of actuator to the function of control, alarm control, data acquisition for electric heating equipment, electromagnetism and electric valve ${ }^{[1]}$. It Supports RS485 serial interface by using standard MODBUS communication protocol RTU. Digital display control instrument has 31 function parameters. These parameters use the standard MODBUS RTU RS485 communication protocol and serial interface transmission to the computer, then the computer acquisition, display and control by using the software of Labview on these parameters, eventually forming a wide variety of computer control systems.

\section{The hardware principle of communication research}

\section{The principle of hardware wiring}

Computer and digital display control instrument hardware wiring diagram as shown in Figure 1. In figure: 1 computer; 2 RS232 and RS485 conversion module; 3, 4, 5 NHR1100 digital display control instrument.

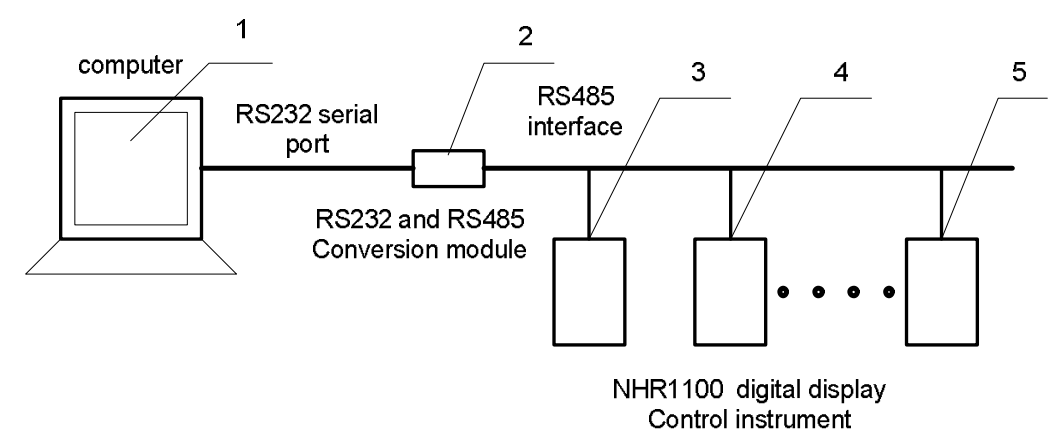

Figure 1 computer and digital display control instrument hardware wiring diagram

Computer's serial communication COM port is connected with the RS232 and RS485 conversion module's RS232 port, the digital display control instrument's RS485 communication terminal A, B is connected with RS485 conversion module's RS485 port.

1.2 Single loop digital display instrument communication parameter setting

Single loop digital display instrument communication parameter setting shown in table $1^{[2]}$. 
Table 1 single-loop digital display communication parameter table

\begin{tabular}{c|c|c|c|c|c|c}
\hline $\begin{array}{c}\text { communicatio } \\
\mathrm{n} \text { port }\end{array}$ & $\begin{array}{c}\text { communication } \\
\text { mode }\end{array}$ & $\begin{array}{c}\text { baud } \\
\text { rate }\end{array}$ & $\begin{array}{c}\text { data } \\
\text { bits }\end{array}$ & $\begin{array}{c}\text { sto } \\
\text { p bit }\end{array}$ & $\begin{array}{c}\text { ch } \\
\text { eck }\end{array}$ & $\begin{array}{c}\text { devic } \\
\text { e address }\end{array}$ \\
\hline COM1 & RS485 & 9600 & 8 & 1 & no & 1 \\
ne
\end{tabular}

\section{Under the Labview software platform a single-loop digital display instrument parameters achieving the principles of reading and writing}

Modbus is invented by Modicon (a brand of Schneider electric company) in 1979, the world's first truly global bus protocol for industrial site. This protocol supports traditional RS-232, RS-422, RS-485 and Ethernet devices. Many industrial equipment, including PLC、DCS、 intelligent instruments and so on , all use the Modbus protocol as a communication standard. Modbus has the following characteristics:(1) Standard, open, users are free and safely using the Modbus protocol, no need to pay a license fee and will not infringe the intellectual property. At present, support Modbus manufacturers more than 400, support Modbus more than 600 kinds of products.(2) Modbus can support a variety of electrical interfaces, such as RS-232, RS-485 etc., and also can be transmitted on a variety of media, such as twisted pair, fiber optic, wireless, etc. . (3)Modbus' frame format is simple, compact and easy to understand. Users are easy to use. Manufacturers are simple to develop ${ }^{[3]}$.

Labview called Laboratory Virtual Instrument Engineering Workbench created by USA National Instruments Corporation (National Instruments, NI). It is a powerful and flexible instrumentation and analysis software application development tools. It is a computer programming language based on graphical, with icons instead of lines of text to create applications. Based on PC in measurement and control software, Labview market penetration rate second only to $\mathrm{C}++/ \mathrm{C}$ language. Labview has been accepted widely by industry, academia and research laboratories, and also recognized as the standard for data acquisition and instrument control software ${ }^{[4]}$.

Single loop digital display instrument parameter data format Single-loop digital display parameter data format shown in Table 2.

Table 2 Single-loop digital display instrument parameter data format table

\begin{tabular}{|l|l|l|l|}
\hline parameter name & unit address & data format & data types \\
\hline instrument Type & 00 & Float & read-only \\
\hline measured value display & 02 & Float & read-write \\
\hline the first alarm value & 04 & Float & read-only \\
\hline the second alarm value & 06 & Float & read-write \\
\hline input indexing number & 48 & Float & read-write \\
\hline decimal point & 50 & Char & read-write \\
\hline the upper limit of measurement range & 51 & Char & read-write \\
\hline the lower limit of measurement range & 57 & Char & read-write \\
\hline parameter password & 58 & Char & read-write \\
\hline device address & 65 & Char & read-write \\
\hline baud rate & 66 & Char & read-write \\
\hline
\end{tabular}

\section{Single-loop digital display parameter data transmission Modbus function package}

Table3 Single-loop digital display parameter data transmission Modbus function package table

\begin{tabular}{c|c|c|c|c|c}
\hline device address & $\begin{array}{c}\text { read } \\
\text { function code }\end{array}$ & $\begin{array}{c}\text { unit start } \\
\text { address }\end{array}$ & $\begin{array}{c}\text { unit } \\
\text { number }\end{array}$ & $\begin{array}{c}\text { check } \\
\text { code }\end{array}$ & note \\
\hline 01 & 03 & 0000 & 0010 & 4406 & $\begin{array}{c}\text { Including: instrument type, the measured } \\
\text { value display, parameter password, the first } \\
\text { alarm value, the second alarm value }\end{array}$ \\
\hline 01 & 03 & 0011 & 0010 & 1403 & $\begin{array}{c}\text { Including: input indexing number, decimal } \\
\text { point, device address, baud rate, the lower limit } \\
\text { of the measurement range }\end{array}$ \\
\hline 01 & 03 & 0021 & 0001 & D400 & the upper limit of measurement range \\
\hline
\end{tabular}




\section{Single-loop digital display parameter data receiving Modbus function package}

Table 4 Single-loop digital display parameter data receiving Modbus function package table

\begin{tabular}{|c|c|c|c|c|c|}
\hline devic & read & & parameter & chec & note \\
\hline $\begin{array}{l}\text { e } \\
\text { address }\end{array}$ & $\begin{array}{l}\text { function } \\
\text { code }\end{array}$ & bytes & $\begin{array}{l}\text { unit data } \\
\text { content }\end{array}$ & $\mathrm{k}$ code & \\
\hline 01 & 03 & 20 & 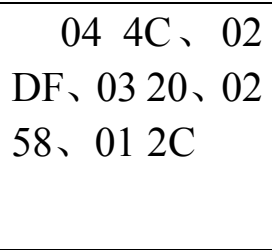 & $\mathrm{D}^{0 \mathrm{CA}}$ & $\begin{array}{l}\text { instrument type }=11100 \text { the } \\
\text { measured value display }=73.5 \\
\text { parameter password }=-800 \text { the } \\
\text { first alarm value }=60 \text { the second } \\
\text { alarm value }=30\end{array}$ \\
\hline 01 & 03 & 20 & $\begin{array}{rrrr}00 & 1 \mathrm{E} 、 & 00 \\
01 、 & 00 & 01 、 & 00 \\
03 、 & 0000 & \end{array}$ & $2^{\mathrm{E} 5 \mathrm{C}}$ & $\begin{array}{l}\quad \text { input indexing number }=27 \\
\text { decimal point }=1 \text { device } \\
\text { address }=21 \text { baud rate }=3 \text { the } \\
\text { lower limit of the measurement } \\
\text { range }=0\end{array}$ \\
\hline 01 & 03 & 02 & 03 E8 & $\mathrm{A}^{\mathrm{B} 8 \mathrm{~F}}$ & $\begin{array}{c}\text { the upper limit } \\
\text { measurement range }=1000\end{array}$ \\
\hline
\end{tabular}

Single-loop digital display parameters indicates the instrument front panel design

Single-loop digital display parameters indicates the instrument front panel shown in figure 2.

Single-loop digital display parameters indicator include: Instrument type, measured value display, parameter password, the first alarm value, the second alarm value, enter indexing number, decimal point, device address, baud rate, the lower limit of the measurement range, the higher limit measurement range.

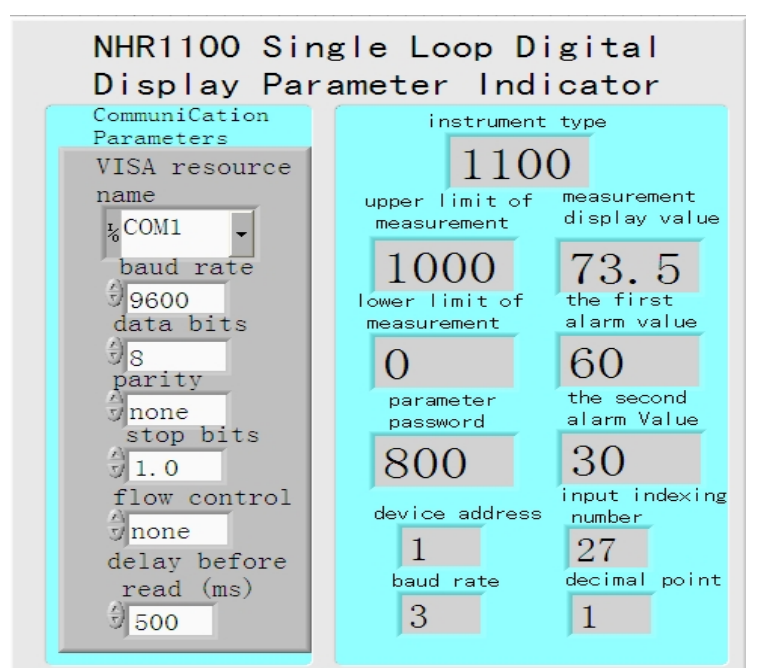

Figure 2 Single-loop digital display parameters indicates the instrument front panel figure

Single-loop digital display parameter indicator programming

Single-loop digital display parameter indicator shown in figure 3.

Including: VISA configure serial port VI, VISA write-in (function), VISA read (function), VISA closed (function), index array (function), Intercept string (function), Cast (function), the conversion (function) from string to byte array and so on. 


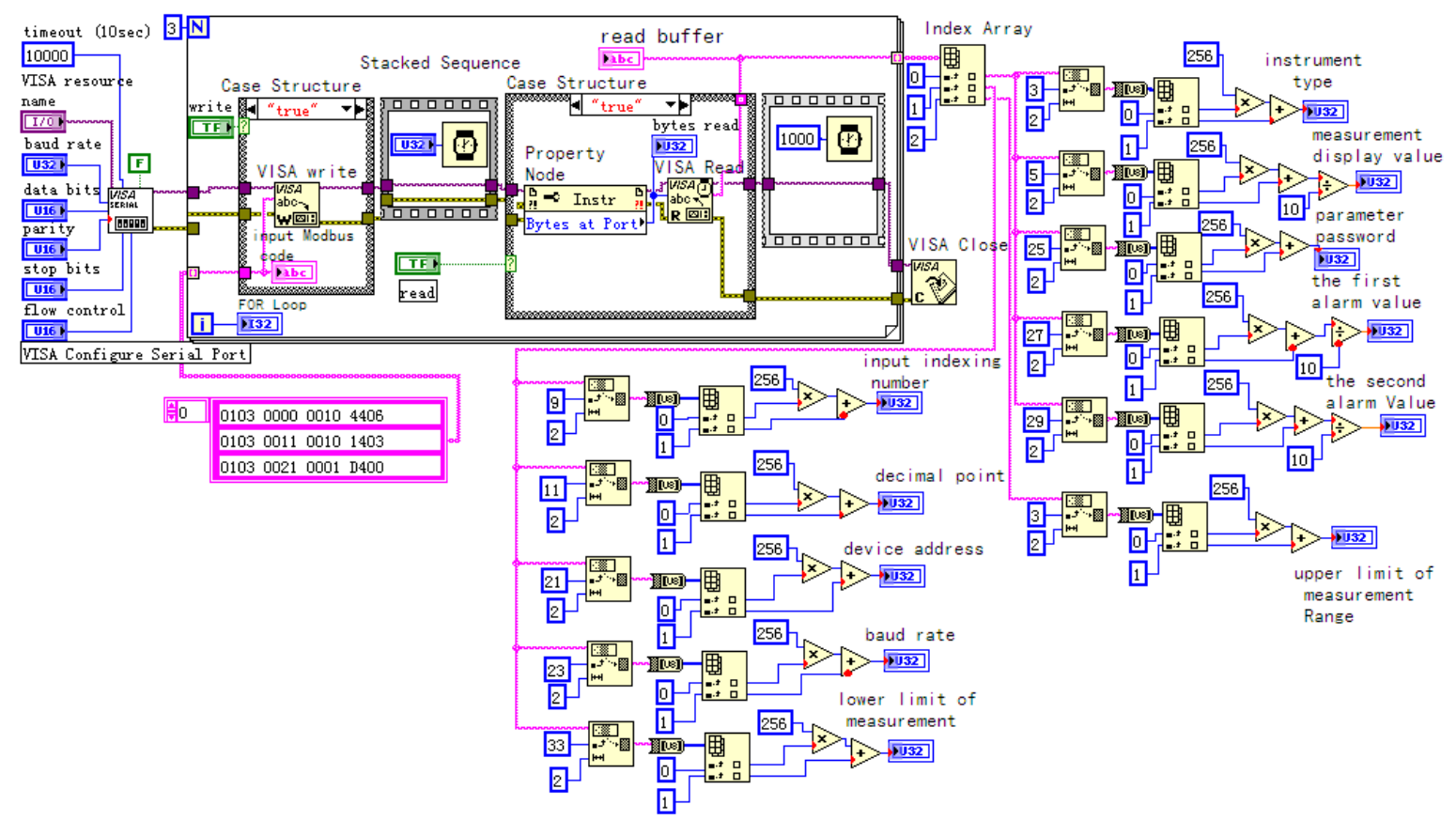

Figure 3 Single-loop digital display parameter indicator figure

VISA configure serial port VI to make the VISA resource name specified serial according to specific initialization settings. VISA write-in (function), makes data of write-in buffer to write VISA resource name specified device or interface. VISA read (function), from VISA resource name specified device or interface read the specified number of bytes and make the data back to the read buffer. VISA closed (function), closes VISA resource name specified device session handle or event object. Index array (function), returns $\mathrm{n}$ dimensional array in the index position elements or subarray. Intercept string (function), returns the input string string, starts from the offset position, contains the length of the characters. For the array input, the function connects each element in the array. Cast (function), by new data types flattening and reduction, makes $\mathrm{x}$ cast to a certain type. If a function can not be converted to data and must be explained, LabVIEW can use a temporary buffer. The conversion (function) from string to byte array makes string converting array of no sign byte ${ }^{[5]}$.

\section{Conclusions}

Single loop digital display indicator parameters, from the two aspects of hardware and software, expound the realization of the intelligent controller parameters in the Labview software platform. Through Labview software platform and the supported MODBUS protocol and RS485 communication interface, it will represent single loop control parameters of digital display control function, acquisition to the computer control system, for industrial automatic control system of data acquisition and monitoring control to lay the foundation.

\section{References}

[1] NHR - 5300 series of artificial intelligent PID controller operation manual, In Chinese.

[2] Information on http://www.hrgs.com.cn

[3] Jinghui zhao, Bing zhou Labview and Modbus communication methods of SR23 island electric regulator. Automation and instrumentation[J], 2014,6: 106-109, In Chinese.

[4] J.H.Zhao, and B.Zhou," Thermocouple automatic verificating device based on virtual instrument technology", Applied Mechanics and Materials Vols. 303-306 (2013) pp 588-596 Online available since 2013/Feb/13 Trans Tech Publications, Switzerland doi:10.4028/www.scientific.net/AMM.303-306.588.

[5] Information on http://www.ni.com/china/labview. 